\title{
Review
}

CARDIOLOGY

\section{Hybrid Revascularization: A Review}

\author{
Tisa Saha Syed Yaseen Naqvi Sheldon Goldberg \\ Pennsylvania Hospital, University of Pennsylvania, Philadelphia, PA, USA
}

\section{Keywords}

Hybrid - Coronary artery - Coronary artery bypass graft . Revascularization - Multivessel disease · Coronary artery disease $\cdot$ Percutaneous coronary intervention

\begin{abstract}
Hybrid coronary revascularization (HCR) combines surgical bypass with percutaneous coronary intervention $(\mathrm{PCl})$ performed either during the same procedure or in a staged approach within 60 days. Coronary artery bypass grafting using the left internal mammary artery (LIMA) has shown excellent long-term patency with improved patient survival. It remains the gold standard treatment for the majority of patients with multivessel coronary artery disease. However, saphenous vein grafts have poor long-term patency. Advances in stent technology have resulted in reduced rates of thrombosis and restenosis, making $\mathrm{PCl}$ a viable alternative to coronary surgery in selected patients. HCR is attractive as a less invasive method of coronary revascularization which preserves the benefits of the LIMA performed with less invasive surgical techniques with the efficacy of newer generation stents.
\end{abstract}

\section{Introduction}

Hybrid coronary revascularization (HCR) combines surgical bypass with percutaneous coronary intervention (PCI) performed either during the same procedure or in a staged approach within 60 days [1].

There are several reasons HCR developed as a revascularization strategy for patients with multivessel coronary artery disease. Coronary artery bypass grafting (CABG) using the left internal mammary artery (LIMA) has excellent long-term patency with improved survival. However, saphenous vein grafts (SVG) have significantly worse long-term patency. As a result, surgeons have attempted all arterial revascularization utilizing several strategies including bilateral mammary, sequential mammary, and radial gastroepiploic arteries, but these approaches may be associated with increased complication rates [2].

Advances in stent technology have resulted in reduced rates of thrombosis and restenosis, making PCI a viable alternative to coronary surgery in selected patients. While multivessel PCI with newer-generation drug-eluting stents (DES) is an attractive strategy, use of the LIMA to the left anterior descending artery (LAD) provides the most predictable long-term results [2-4]. The hybrid approach takes advantage of the best features of percutaneous and surgical revascularization approaches. The volume of hybrid coronary revascularization in the US comprises only $0.5 \%$ of the volume of CABG operations [5].

\section{KARGER}

(c) 2018 S. Karger AG, Basel

E-Mail karger@karger.com

www.karger.com/crd
Dr. Tisa Saha

Pennsylvania Hospital, University of Pennsylvania

800 Spruce Street

Philadelphia, PA 19107(USA)

E-Mail tisa.saha@uphs.upenn.edu 
However, because of the efficacy of newer generation stents, combined with more sophisticated simplified surgical techniques, the volume of hybrid procedures is expected to increase $[1,5,6]$.

\section{Evolution of Surgical Bypass Techniques}

One of the major disadvantages of a standard CABG is the median sternotomy incision, with the attendant discomfort and temporary limitations on activity as well as the risks of complications including sternal instability and infection causing delayed recovery. Patients undergoing a standard CABG also often require cardiopulmonary bypass, and manipulation of the aorta increases the risk of stroke and reduced cognitive function [7-9]. Accordingly, surgical techniques have evolved with the goal of minimizing complications while attempting to achieve long-term patency of bypass grafts.

\section{Off-Pump CABG}

Off-pump CABG is a safe and effective approach to surgical revascularization. While this technique avoids the consequences of cardiopulmonary bypass, performing surgery on a beating heart can be complicated by hemodynamic compromise due to reduced venous return and cardiac output associated with manipulation of the heart. This type of operation is technically challenging and has been associated with decreased graft patency; however, the use of instruments to stabilize the myocardium and improve visualization of the distal anastomotic site has improved results. The use of an intracardiac shunt, which bypass coronary artery flow, allows for more precise sewing of the anastomosis, too [10]. However, a 5 -year study comparing on-pump versus off-pump bypass surgery noted a slightly higher mortality (15.2 vs. $11.9 \%$ ) in the off-pump group [11].

\section{Minimally Invasive Techniques}

CABGs can be performed via a left-sided thoracotomy between the 4 th/5th interspace with special retractors suited for smaller incisions $(4-5 \mathrm{~cm})$. A smaller incision reduces postoperative discomfort and risk of infection as well as speeds recovery [12]. Although the LIMA is under direct visualization, doing this surgery through a smaller incision with a beating heart is technically challenging. Endoscopic atraumatic CABG can be performed via thoracoscopic incisions. This approach requires single lung ventilation and $\mathrm{CO}_{2}$ insufflation but provides better visualization than a mini-left thoracotomy.
Lastly, totally endoscopic CABG surgery (TECAB) is also available using the Da Vinci robotic system. The anastomosis can be made on a beating heart with a suture technique or without sutures utilizing an anastomotic connector device. However, TECAB is contraindicated in patients with severe pulmonary disease and hemodynamic instability, and for intramyocardial coronary arteries. TECAB is limited by a $10 \%$ conversion rate to standard CABG and the requirement of expensive technology and training [10].

\section{Use of All Arterial Revascularization}

One of the limitations of a standard CABG is poor SVG patency compared to PCI with newer generation DES. Although results vary widely, about $20 \%$ of vein grafts occlude in the 1st year, and by 10 years, vein graft patency is less than $50 \%$ due to an accelerated form of atherosclerosis $[13,14]$. Despite these findings, SVG continue to be used in approximately $75 \%$ of patients even in experienced centers. Surgeons have sought to overcome the problem of poor SVG patency by performing all arterial revascularization. The most common approach is to use both mammary arteries. The Arterial Revascularization Trial (ART) did not show any significant difference between single (SIMA) and bilateral internal mammary artery (BIMA) mortality outcomes at the 5-year followup; however, sternal wound complications were more prevalent in the bilateral artery approach group [15]. Sternal reconstruction rates were $1.9 \%$ in the BIMA group versus $0.6 \%$ in the SIMA group [16]. However, the ART post hoc analysis showed that using an additional radial artery rather than SVG during a SIMA or BIMA is associated with a lower risk of major adverse cardiac events in patients undergoing CABG [17]. The outcomes of a 10year follow up are still pending.

\section{Evolution of DES and Percutaneous Techniques}

First-generation DES (sirolimus and paclitaxel eluting) are associated with a $2 \% 1$-year and up to $5 \% 10$-year risk of stent thrombosis [18]. The development of second-generation stents with thinner struts, more compatible polymers, and effective cytostatic drugs resulted in reductions in mortality (0.4 vs. $3.1 \%$ ) and major adverse cardiovascular and cerebral events (MACCE) in patients with multivessel disease $[19,20]$.

In patients with multivessel disease, target vessel revascularization rates were $14.6 \%$ in the DES PCI group and $6.8 \%$ in the CABG group $(p<0.001)$. This contributed to a higher MACCE in PCI (21.2 vs. 16.3\%) [21]. PCI
Saha/Naqvi/Goldberg 


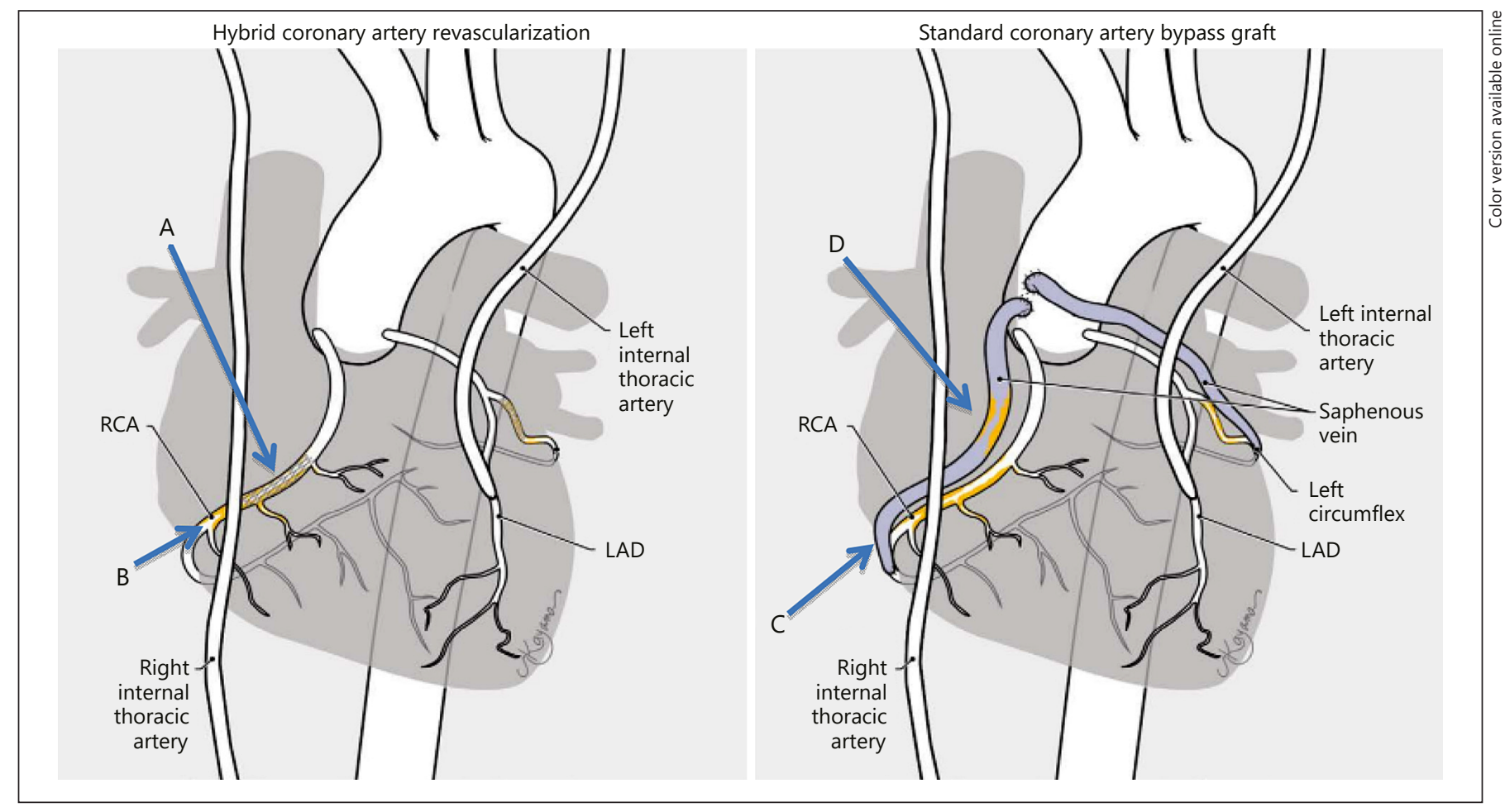

Fig. 1. Drug-eluting stents can effectively treat the culprit lesion in a non-LAD vessel. However, these patients may require re-intervention due to stent thrombosis and restenosis (A) or disease progression distal to the stent (B). While saphenous vein grafts bypass the entire coronary vessel avoiding the problem (C) with disease progression, accelerated atherosclerosis within the venous conduit itself is associated with high rates of occlusion (D).

using newer everolimus stents in patients with low to intermediate angiographic risk scores is noninferior to CABG with similar rates of death, myocardial infarction (MI), and stroke at 3 years [22]. Although newer-generation DES have decreased risks of thrombosis and restenosis, the need for target vessel revascularization remains a concern for patients undergoing a hybrid procedure [3, 5]. Similarly, repeat revascularization was higher in HCR than standard CABG due to disease in non-LAD locations (3.8\% HCR vs. $1.4 \%$ CABG after 1 year) [3]. MACCE rates in patients undergoing multivessel PCI were significantly higher than in patients undergoing HCR due to repeat revascularization of the LAD in the PCI group (22.7 vs. $6.4 \%, p<0.001$ ) (Fig. 1) [23].

\section{Indications for Hybrid Revascularization}

The 2012 ACC/AHA guidelines recommend HCR for patients with heavily calcified proximal aortas, poor bypass conduits and landing targets for non-LAD vessels that are otherwise amenable for PCI. Use of the LIMA as part of a hybrid procedure is especially advantageous if there is complex LAD anatomy making that vessel relatively unsuitable for PCI. Specific features that make the LAD unsuitable include heavily calcified lesions, tortuosity, bifurcation lesions, and chronic total occlusions (class IIa, level B evidence). HCR should also be considered for patients in whom HCR would improve the risk-benefit ratio compared to CABG or PCI (class IIb, level C evidence) [24]. Patients with multiple comorbidities such as malignancies, diabetics with a high risk of wound infections, severe obesity, or frailty may also be considered for HCR (Table 1) [25].

In order to perform the hybrid procedure, patients should have a LIMA harvest possible using minimally invasive or endoscopic approaches. Patient characteristics such as deconditioning, difficult rehabilitation, and reluctance to undergo median sternotomy may also play a role in decision-making leaning towards HCR [26].

Conversely, if lesions in the right or left circumflex coronary arteries have a complex anatomy and require multiple stents, are highly calcific, or are chronically totally occluded, then HCR is not recommended $[27,28]$. 
Table 1. Hybrid coronary revascularization

\begin{tabular}{lc}
\hline Indications & Contraindications \\
\hline Inadequate or poor quality of venous conduits & Clinical characteristics \\
History of a prior CABG & Coagulopathies and contraindications to dual antiplatelet therapy \\
Poor graft insertion sites in non-LAD lesions & Severe chronic obstructive pulmonary disease \\
Non-LAD lesions amendable to PCI & Pulmonary hypertension \\
LAD lesion not amendable to PCI & Access limiting PVD \\
Severe aortic and mitral calcification & Need for additional procedures such as valve repairs \\
Previous chest radiation & Anatomy \\
& Complex non-LAD lesion requiring multiple stents or overlapping \\
& Poor LIMA graft quality or anastomosis site \\
& Logistic limitations \\
& Lack of hybrid OR (concurrent procedures) \\
& Paucity of experience and surgeon comfort level to harvest LIMA \\
via a minimal incision or an endoscopic approach
\end{tabular}

CABG, coronary artery bypass grafting; LAD, left anterior descending artery; LIMA, left internal mammary artery; PCI, percutaneous coronary intervention; OR, operating room; PVD, peripheral vascular disease.

\section{Concurrent versus Staged HCR}

Current data suggests no differences in hospital death, MI, stroke, and repeat revascularization in staged versus concurrent procedures [3].

\section{Concurrent Procedures}

Concurrent procedures performed in a specially constructed hybrid suite provide the ability to switch to an open procedure if necessary [3]. This procedure also allows complications to be resolved immediately and avoids the need for 2 separate procedures. Real-time angiography may be performed after the completion of LIMA anastomosis to assure the quality of the anastomosis and permit revision if needed [14].

There was a discrete proximal right coronary artery lesion, easily treated with DES placement. The patient had dual antiplatelet therapy (DAPT) administered after the surgical portion of the procedure, thus minimizing the bleeding risk. He was discharged after 2 days and remained asymptomatic at the 6-month follow-up.

Undergoing multivessel revascularization in one setting in a concurrent approach also reduces contrast and anesthetic exposure and hence provides greater efficien$c y$, shortens length of stay, and improves patient satisfaction (Fig. 2a, b) $[3,5,13]$.

However, the bleeding risk is greater if DAPT is utilized [29]. Concurrent HCR could reduce the risk of bleeding with a "modified antiplatelet and anticoagulation protocol," which includes continuous use of aspirin perioperatively and a loading dose thienopyridines immediately before PCI [30]. The risk of stent thrombosis may also be greater due to the proinflammatory milieu during surgery $[25,31]$.

\section{Staged - Surgery Followed by PCI}

Surgery followed by PCI is the most frequently used approach. Bleeding risk is reduced when DAPT is administered after anastomosis completion. This approach is more challenging and time consuming for the surgeons depending on the learning curve especially while non-LAD regions still remain suboptimally perfused before PCI [26]. The advantages of surgical anastomosis followed by PCI provide a protected LAD and allows aggressive use of antiplatelet therapy to reduce the risk of stent thrombosis [24, 31]. Disadvantages include a higher cost [10]. Patients in this group may be at risk of a second surgery if PCI fails or complications occur following surgical anastomosis [1].

\section{Staged - PCI Followed by Surgery}

PCI followed by surgery is useful in patients with an emergent need for left circumflex or right coronary artery revascularization such as in an acute MI followed by surgical revascularization if there is also a nonurgent complex LAD lesion present on angiogram [25].

The disadvantages include PCI with an unprotected LAD and increased risk of bleeding during subsequent CABG [26]. With PCI already performed, angiographic confirmation is also not readily available should any complications arise from the PCI or surgery [5]. Interruption of
Saha/Naqvi/Goldberg 

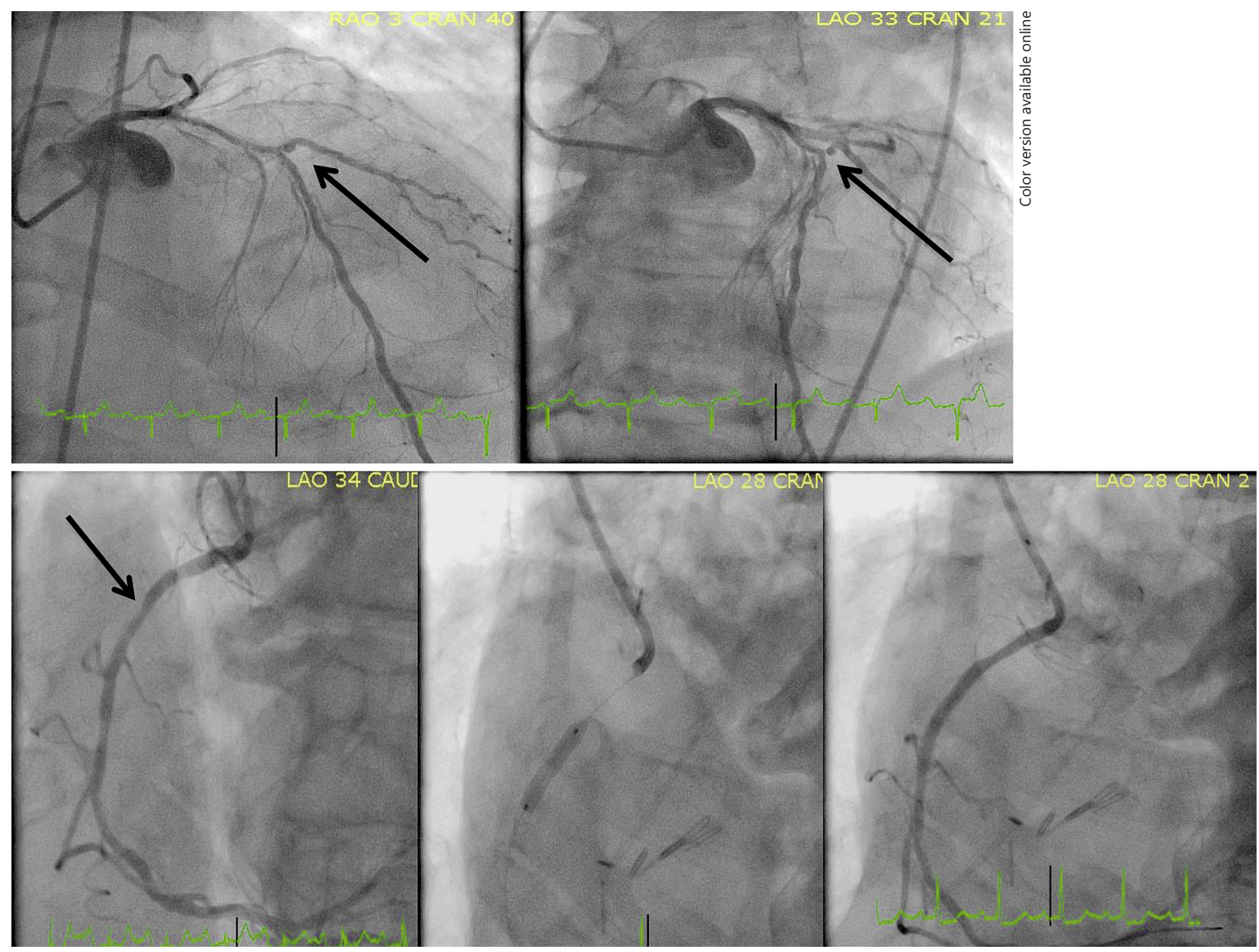

Fig. 2. Angiograms of an 80 -year-old man who presented with angina and was evaluated for a concurrent hybrid procedure. He received off-pump coronary artery bypass grafting with a left internal mammary artery (LIMA) to the left anterior descending artery (LAD) via left thoracotomy for a calcified bifurcation lesion. Black arrows indicate $\mathrm{LAD} /$ diagonal bifurcation lesion with a stenosis of the ostium.

DAPT prior to surgery is associated with an increased risk of stent thrombosis [25]. Regardless of which is performed first, the disadvantages of a staged procedure include having 2 teams, 2 handoffs, and a longer length of stay [5].

\section{Outcomes of HCR}

\section{Standard $C A B G$ versus $H C R$}

The majority of the head-to-head comparisons that are available currently are driven from compiled metaanalyses of smaller studies due to the lack of larger multicentered randomized studies (Table 2). In general, most of the meta-analyses conclude that HCR is noninferior to CABG in terms of cumulative MACCE; however, some reports emphasized that repeat revascularization was more often required in the HCR group.

In terms of short-term outcomes, there is no difference in 30-day and 1-year outcomes including inhospital MI, stroke, or death for HCR versus standard CABG [3]. Patients undergoing HCR required fewer transfusions and had reduced length of stay in the intensive care unit compared to patients undergoing standard CABG $[3,34]$. Inhospital events, including reoperation, renal failure, ventilator duration, and infections, were significantly lower in the HCR (8.5\%) than the CABG group (15.5\%) ( $p=$ 0.005 ) [32]. The quality of life 6 weeks after discharge was better in the HCR group [3]. These attributes are secondary to the less invasive nature of a minimal incision compared to a cardiopulmonary bypass and sternotomy. 
Table 2. Summary of major meta-analyses comparing hybrid coronary revascularization (HCR) to a standard coronary artery bypass grafting (CABG)

\begin{tabular}{|c|c|c|c|c|c|c|c|c|c|c|}
\hline $\begin{array}{l}\text { First } \\
\text { author, } \\
\text { year }\end{array}$ & $\begin{array}{l}\mathrm{Pa}- \\
\text { tients, } \\
n\end{array}$ & $\begin{array}{l}\text { Studies, } \\
n\end{array}$ & HCR & CABG & Death & MI & Stroke & $\mathrm{RR}$ & MACCE & Conclusions \\
\hline $\begin{array}{l}\text { Zhu }[8] \\
2015\end{array}$ & 6,176 & 10 & 623 & 5,553 & $\begin{array}{l}1.76 \mathrm{vs} . \\
1.67 \% \\
p=0.64\end{array}$ & $\begin{array}{l}1.1 \text { vs. } \\
0.6 \% \\
p=0.54\end{array}$ & $\begin{array}{l}1.1 \text { vs. } \\
1.1 \% \\
p=0.81\end{array}$ & $\begin{array}{l}0 \text { vs. } \\
0.28 \% \\
p=0.68\end{array}$ & $\begin{array}{l}2.5 \text { vs. } \\
3.5 \% \\
p=0.26\end{array}$ & $\begin{array}{l}\text { HCR noninferior to CABG inhospital and 1-year } \\
\text { follow-ups }\end{array}$ \\
\hline $\begin{array}{l}\text { Hu [14] } \\
2015\end{array}$ & 5,453 & 7 & 422 & 5,031 & $\begin{array}{l}\text { No diff. } \\
\text { (in hospital) } \\
p=0.47\end{array}$ & $\begin{array}{l}\text { Not } \\
\text { discussed }\end{array}$ & $\begin{array}{l}\text { Not } \\
\text { discussed }\end{array}$ & $\begin{array}{l}\text { Not } \\
\text { discussed }\end{array}$ & $\begin{array}{l}\text { No diff. } \\
\text { (in hospital) } \\
p=0.34\end{array}$ & $\begin{array}{l}\text { HCR did not improve survival compared to CABG but } \\
\text { decreased secondary outcomes: blood transfusions, } \\
\text { length of ICU stay and intubation; HCR also increased } \\
\text { inhospital costs }\end{array}$ \\
\hline $\begin{array}{l}\text { Harskamp } \\
{[3], 2014}\end{array}$ & 1,190 & 6 & 366 & 824 & $\begin{array}{l}3 \text {-year } \\
\text { mortality: } \\
4.5 \text { vs. } \\
7.3 \% \\
p=0.51\end{array}$ & $\begin{array}{l}0.6 \text { vs. } \\
1.5 \% \\
p=0.39\end{array}$ & $\begin{array}{l}\text { At } 1 \text { year: } \\
0 \text { vs. } \\
2.4 \% \\
p=0.31\end{array}$ & $\begin{array}{l}3 \text { years } \\
8.3 \text { vs. } \\
3.4 \% \\
p<0.001\end{array}$ & $\begin{array}{l}1 \text { year } \\
4.1 \text { vs. } \\
9.1 \% \\
p=0.13\end{array}$ & $\begin{array}{l}\text { HCR MACCE events are comparable to CABG } \\
\text { outcomes during inhospital stay and at } 1 \text { year, but RR } \\
\text { is more frequently seen in patients treated with HCR } \\
\text { (especially greater need for LAD revascularization and } \\
\text { nontarget lesion revascularization from native disease } \\
\text { progression) }\end{array}$ \\
\hline $\begin{array}{l}\text { Harskamp } \\
{[32], 2015}\end{array}$ & 668 & 6 & 325 & 343 & $\begin{array}{l}4.9 \text { vs. } \\
8.2 \% \\
p=0.24\end{array}$ & $\begin{array}{l}2.2 \text { vs. } \\
4.4 \% \\
p=0.2\end{array}$ & $\begin{array}{l}0.6 \text { vs. } \\
2.9 \% \\
p=0.039\end{array}$ & $\begin{array}{l}6.9 \text { vs. } \\
2.1 \% \\
p<0.001\end{array}$ & $\begin{array}{l}8.6 \text { vs. } \\
11.6 \% \\
p=0.24\end{array}$ & $\begin{array}{l}\text { HCR reduces risks of strokes compared to CABG but } \\
\text { increases need for RR }\end{array}$ \\
\hline $\begin{array}{l}\text { Phan }[33] \text {, } \\
2014\end{array}$ & 1,664 & 8 & 505 & 1,159 & $\begin{array}{l}30 \text { days: } \\
1 \text { vs. } \\
1.3 \% \\
p=0.8\end{array}$ & $\begin{array}{l}5.7 \text { vs. } \\
4.9 \% \\
p=0.01\end{array}$ & $\begin{array}{l}0.7 \text { vs. } \\
0.7 \% \\
p=0.96\end{array}$ & $\begin{array}{l}11.3 \text { vs. } \\
3.2 \% \\
p<0.0001\end{array}$ & $\begin{array}{l}1.7 \text { vs. } \\
3.4 \% \\
p=0.31\end{array}$ & $\begin{array}{l}\text { HCR is associated with fewer MI and shorter hospital } \\
\text { stay but greater need for RR }\end{array}$ \\
\hline
\end{tabular}

All percentages are comparisons of HCR to CABG. diff., difference; MACCE, major adverse cardiovascular and cerebral events; MI, myocardial infarction; RR, repeat revascularization.

Bypass time $>100 \mathrm{~min}$ is a risk factor for major infection [35]. LIMA harvest can be time consuming as it still depends on the learning curve through smaller left thoracotomy incision. Angiography during the hybrid procedure provides confirmation of graft patency when PCI is followed by surgery [7]. The conversion from HCR to a standard CABG occurred in $6.1 \%$ of cases [10]. In HCR, long-term survival rate is $92.5-100 \%$ at 1 year and $93 \%$ at 5 years [10]. In the HCR group, the LIMA patency over 3-5 years ranged from $93-100 \%$, and re-intervention on the LAD anastomosis was low at $1-4 \%$ [10]. Non-LAD revascularization was most frequently required in patients with diabetes [25].

Compared to standard CABG, heart teams opted for HCR due to poor grafts and conduits $43.4 \%$ of the time and to minimize surgical risk $47.8 \%$ of the time [4]. A useful tool to assess disease severity based on angiographic findings, the SYNTAX score, allows stratification of patients according to lesion complexity and the amount of myocardium at risk. In patients with increased disease complexity, triple vessel disease, and high-tointermediate SYNTAX score, a standard CABG is preferred $[4,5]$.

\section{PCI versus HCR}

In HCR, stent restenosis ranged from 9 to $13 \%$, and thrombosis ranged from 2.2 to $3.7 \%$ [10, 36, 37]. One of the causes of non-LAD revascularization was stent thrombosis (in bare-metal stents and DES), which was as high as $6 \%$ in a small study including 100 patients followed for a mean of 5 years [25]. The risk of stent thrombosis is highest if PCI is performed before a surgery secondary to DAPT interruption beforehand [10]. These rates are similar to DES thrombosis rates noted in the SYNTAX trial, which utilized older-generation stents (3.3\% at 12 months) $[38,39]$. Guidelines established following the SYNTAX trial for patients with left main disease recommend that patients with low to intermediate syntax score (0-32) may undergo PCI as a class $2 \mathrm{a}$ or $2 \mathrm{~b}$ indication [40]. Of note, a head-to-head comparison between SVG performance against newer-generation DES is lacking.

\section{HCR versus BIMA}

Five percent of coronary artery bypass surgery utilizes BIMA [1]. Although there is no difference in 5-year mortality rates, sternal wound infections and reconstruction rates were greater in patients undergoing BIMA than SIMA CABG [2]. Based on the Society of Thoracic Sur- 
geons database, the predicted mortality risk in HCR is 1.6 versus 1.1\% in BIMA conduits [34]. A direct comparison of BIMA revascularization with HCR is still lacking.

\section{HCR versus On-Pump and Off-Pump CABG}

HCR avoids the consequences of a cardiopulmonary bypass, aortic cross clamping, and sternotomy [3]. Coronary occlusion time is significantly shorter in HCR (single graft placement and 30-second intervals for stent placements) than off-pump CABG (8-12 min per anastomosis). Troponin leaks are lower, and recovery is quicker in HCR patients $[14,41]$. The all-cause mortality was similar ( $1.2 \%$ on pump vs. $1.1 \%$ off pump at 1 month and $2.5 \%$ on pump vs. $2 \%$ off pump at 1 year) [42]. However, graft patency is better with on-pump revascularization [6].

\section{HCR Outcomes in High-Risk Groups}

Patients in the high-risk group (SYNTAX score $>32$ ) performed better with a standard CABG than HCR (mortality risk of 7.5 vs. $23 \%$ ) [10, 43, 44]. The MACCE and target vessel revascularization rates were higher in the HCR group in patients with a SYNTAX score of $\geq 22$ [25]. Repeat revascularization in patients with higher SYNTAX scores makes HCR less desirable than CABG.

\section{Stroke}

Stroke rates are lower in off-pump CABG $(0.14 \%)$ and on-pump beating-heart CABG (0\%) but higher in cardioplegic CABG (0.5\%) [35]. There is an increased risk of stroke in patients undergoing CABG due to cardiopulmonary bypass and surgery on the ascending aorta [8]. The risk of stroke increases in elderly patients. In a study comparing HCR to CABG in patients over 65 years old, stroke rates were approximately $1.4 \%$ in both groups [27].

Stroke prevention methods should include epiaortic ultrasound to assess aortic calcifications and the burden of atherosclerosis [45]. DAPT after concurrent HCR may help reduce stroke rates [13]. Whether DAPT after concurrent HCR prevents postoperative strokes needs to be further evaluated to formulate guidelines on therapy depending on the type of HCR performed (concurrent, PCI first vs. LIMA to LAD first) [46].

\section{Limitations of the HCR Procedure}

The limitations of HCR include a potentially longer operative time as a result of inexperience and working through small incisions [26]. Successful HCR heavily relies on the quality of anastomosis. LIMA failure can have severe long- term implications [3]. While patency is still $>95 \%, 2$ studies that assessed long-term outcomes of LIMA failure showed a higher prevalence in HCR compared to standard CABG. This may in part be due to increased detection when completion angiography is performed $[47,48]$. Seven percent of LIMA grafts in standard CABG have angiographic evidence of defects, and angiographic confirmation may be helpful in revising the anastomosis in HCR [49].

Revascularization may be less complete in HCR, and long-term effects of underrevascularization are yet to be determined. Long-term data on MACCE are lacking for emergent conversion of off-pump bypass [50]. Patients who were converted from an off-pump to on-pump CABG had a higher mortality rate [35]. Other limitations of HCR also include limited guidelines for patient selection $[34,51]$. While the initial hospitalization is relatively shorter and more cost effective, the uncertainty of longterm outcomes especially with newer stents, subsequent hospitalization for restenosis, and further angiograms must also be evaluated (Fig. 3) [5].

\section{Future Direction}

Long-term outcomes of HCR relative to the type of coronary anatomy and comorbidities need further evaluation. Furthermore, development of an optimal antiplatelet regimen requires refinement. Currently, thienopyridines are administered either after CABG or after PCI but without definite guidelines [26]. The use of agents which reduce the bleeding risk (tranexamic acid) may make surgery safer in patients who require DAPT in staged and concurrent procedures [52]. The role of HCR is expected to grow with the aging patient population with multiple comorbid conditions and complex diseases.

Heart team discussions should weigh the benefits of a minimally invasive procedure in a poor surgical candidate against the complications such as repeat revascularization in those with greater disease burden or higher SYNTAX scores. The data are limited mainly because of selection bias, lack of direct comparison to other modes of treatment (PCI/ $\mathrm{CABG}$ ), lack of randomization, the retrospective nature of published studies, and small sample sizes. The strikingly reduced thrombosis rates with newer antiplatelets such as prasugrel and ticagrelor and restenosis rates with newer generation stents will promote a greater use of HCR [23].

Clopidogrel and prasugrel are 2 commonly used antiplatelets for DAPT purposes. While prasugrel is superior to clopidogrel with respect to potency, they irreversibly bind to the P2Y12 receptor, which creates a bleeding risk 


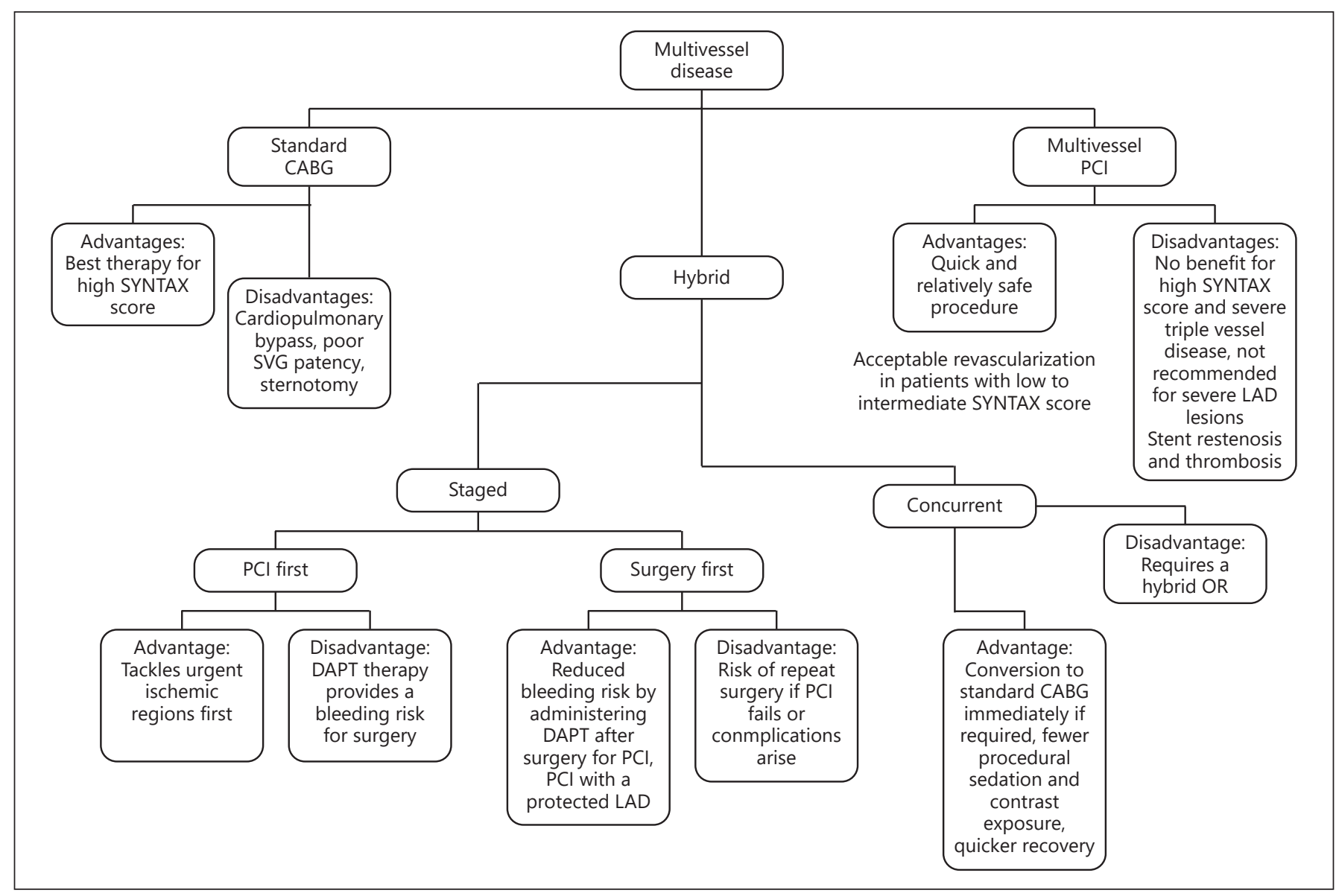

Fig. 3. Flowchart of current treatment of multivessel disease. CABG, coronary artery bypass grafting; DAPT, dual antiplatelet therapy; LAD, left anterior descending artery; OR, operating room; PCI, percutaneous coronary intervention; SVG, saphenous vein graft.

when used around the time of surgery. Due to a faster onset, ticagrelor may be more useful in concurrent procedures immediately following surgery or even prior to surgery due to reversible mechanism of action [53]. Cangrelor is another novel rapid-acting intravenous medication that has shown to reduce acute stent thrombosis and MI rates without increasing bleeding risk compared to clopidogrel [54]. The implications of these findings in HCR have not been evaluated.

Given the absence of randomized trials, a major study will be undertaken: the HCR Pivotal trial. This will compare outcomes of a standard HCR to drug-eluting metallic stent PCI (including the LAD) in patients with multivessel disease [55].

Coronary bypass surgery has remained the gold standard for revascularization in patients with multivessel disease. However, improvements in PCI technology, coupled with advances in minimally invasive surgical tech- niques, now make it possible to consider a hybrid approach in carefully selected patients. To this end, a heart team approach with a careful review of patients' clinical and anatomic characteristics should be utilized.

\section{Conflict of Interest}

The authors have no conflict of interest to disclose.

\section{Funding Sources}

The authors did not receive any funding.

\section{Author Contributions}

All authors had access to data and were involved in writing the manuscript. 


\section{References}

1 Harskamp RE: Current state and future direction of hybrid coronary revascularization. Curr Opin Cardiol 2015;30:643-649.

-2 Taggart DP, Altman DG, Gray AM, Lees B, Gerry S, Benedetto U, Flather M: Randomized trial of bilateral versus single internal-thoracic-artery grafts. N Engl J Med 2016;375:25402549.

3 Harskamp RE, Bagai A, Halkos ME, Rao SV, Bachinsky WB, Patel MR, de Winter RJ, Peterson ED, Alexander JH, Lopes RD: Clinical outcomes after hybrid coronary revascularization versus coronary artery bypass surgery: a meta-analysis of 1,190 patients. Am Heart J 2014;167:585-592.

4 Harskamp RE, Brennan JM, Xian Y, Halkos ME, Puskas JD, Thourani VH, Gammie JS, Taylor BS, de Winter RJ, Kim S, O’Brien S, Peterson ED, Gaca JG: Practice patterns and clinical outcomes after hybrid coronary revascularization in the United States: an analysis from the Society of Thoracic Surgeons adult cardiac database. Circulation 2014;130: 872-879.

5 Gosev I, Leacche M: Hybrid coronary revascularization: the future of coronary artery bypass surgery or an unfulfilled promise? Circulation 2014;130:869-871.

6 Sabik JF 3rd: On-pump coronary revascularization should be our preferred surgical revascularization strategy. J Thorac Cardiovasc Surg 2014;148:2472-2474.

7 Modrau IS, Holm NR, Maeng M, Botker HE, Christiansen EH, Kristensen SD, Lassen JF, Thuesen L, Nielsen PH; Hybrid Coronary Revascularization Study Group: one-year clinical and angiographic results of hybrid coronary revascularization. J Thorac Cardiovasc Surg 2015;150:1181-1186.

8 Zhu P, Zhou P, Sun Y, Guo Y, Mai M, Zheng $S$ : Hybrid coronary revascularization versus coronary artery bypass grafting for multivessel coronary artery disease: systematic review and meta-analysis. J Cardiothorac Surg 2015; 10:63.

-9 Hassell ME, Nijveldt R, Roos YB, Majoie CB, Hamon M, Piek JJ, Delewi R: Silent cerebral infarcts associated with cardiac disease and procedures. Nat Rev Cardiol 2013;10:696706.

10 Ejiofor JI, Leacche M, Byrne JG: Robotic CABG and hybrid approaches: the current landscape. Prog Cardiovasc Dis 2015;58:356-364.

-11 Shroyer AL, Hattler B, Wagner TH, Collins JF, Baltz JH, Quin JA, Almassi GH, Kozora E, Bakaeen F, Cleveland JC Jr, Bishawi M, Grover FL: Five-year outcomes after on-pump and off-pump coronary-artery bypass. N Engl J Med 2017;377:623-632.

12 Aubin H, Akhyari P, Lichtenberg A, Albert A: Additional right-sided upper "half-mini-thoracotomy" for aortocoronary bypass grafting during minimally invasive multivessel revascularization. J Cardiothorac Surg 2015;10: 130.
13 Song Z, Shen L, Zheng Z, Xu B, Xiong H, Li L, Hu S: One-stop hybrid coronary revascularization versus off-pump coronary artery bypass in patients with diabetes mellitus. J Thorac Cardiovasc Surg 2016;151:16951701.e1.

14 Hu FB, Cui LQ: Short-term clinical outcomes after hybrid coronary revascularization versus off-pump coronary artery bypass for the treatment of multivessel or left main coronary artery disease: a meta-analysis. Coron Artery Dis 2015;26:526-534.

15 Taggart DP, Altman DG, Gray AM, Lees B, Gerry S, Benedetto U, Flather M: Randomized trial of bilateral versus single internal-thoracic-artery grafts. N Engl J Med 2016;375:2540-2549.

16 Gatti G: Sternal wound management after bilateral internal thoracic artery grafting: a significant detail. Ann Transl Med 2017;5:262.

17 Taggart DP, Altman DG, Flather M, Gerry S, Gray A, Lees B, Benedetto U: Associations between adding a radial artery graft to single and bilateral internal thoracic artery grafts and outcomes: insights from the Arterial Revascularization Trial. Circulation 2017;136:454463.

18 Yamaji K, Raber L, Zanchin T, Spitzer E, Zanchin C, Pilgrim T, Stortecky S, Moschovitis A, Billinger M, Schonenberger C, Eberli F, Juni P, Luscher TF, Heg D, Windecker S: Tenyear clinical outcomes of first-generation drug-eluting stents: the Sirolimus-Eluting vs Paclitaxel-Eluting Stents for Coronary Revascularization (SIRTAX) VERY LATE trial. Eur Heart J 2016;37:3386-3395.

19 Rodriguez AE: Second versus first generation DES in multiple vessel disease and unprotected left main stenosis: insights from ERACI IV Study. Minerva Cardioangiol 2015;63:317-327.

20 Nakayoshi T, Ueno T, Sasaki KI, Yokoyama S, Ohtsuka M, Mitsutake Y, Itaya N, Chibana H, Sasaki M, Ishimatsu T, Kimura T, Fukumoto Y: Differential angioscopic findings of neointimal coverage among first-, second-, and next generation drug-eluting stents. Int J Cardiol 2016;223:450-451.

21 From AM, Al Badarin FJ, Cha SS, Rihal CS: Percutaneous coronary intervention with drug-eluting stents versus coronary artery bypass surgery for multivessel coronary artery disease: a meta-analysis of data from the ARTS II, CARDia, ERACI III, and SYNTAX studies and systematic review of observational data. EuroIntervention 2010;6:269276.

22 Stone GW, Sabik JF, Serruys PW, Simonton CA, Genereux P, Puskas J, Kandzari DE, Morice MC, Lembo N, Brown WM 3rd, Taggart DP, Banning A, Merkely B, Horkay F, Boonstra PW, van Boven AJ, Ungi I, Bogats G, Mansour S, Noiseux N, Sabate M, Pomar J, Hickey M, Gershlick A, Buszman P, Bochenek A, Schampaert E, Page P, Dressler O, Kosmidou I, Mehran R, Pocock SJ, Kappetein AP: Everolimus-eluting stents or bypass sur- gery for left main coronary artery disease. N Engl J Med 2016;375:2223-2235.

23 Toeg H, Al-Atassi T, Labinaz M, Le May M, Ruel M: Hybrid approach for coronary artery revascularization: where do we stand? Curr Opin Cardiol 2014;29:534-541.

24 Fihn SD, Gardin JM, Abrams J, Berra K, Blankenship JC, Douglas PS, Foody JM, Gerber TC, Hinderliter AL, King SB 3rd, et al: 2012 ACCF/AHA/ACP/AATS/PCNA/SCAI/STS guideline for the diagnosis and management of patients with stable ischemic heart disease: a report of the American College of Cardiology Foundation/American Heart Association Task Force on Practice Guidelines, and the American College of Physicians, American Association for Thoracic Surgery, Preventive Cardiovascular Nurses Association, Society for Cardiovascular Angiography and Interventions, and Society of Thoracic Surgeons. J Am Coll Cardiol 2012;60:e44-e164.

25 Repossini A, Tespili M, Saino A, Di Bacco L, Giroletti L, Rosati F, Bisleri G, Muneretto C: Hybrid coronary revascularization in $100 \mathrm{pa}-$ tients with multivessel coronary disease. Ann Thorac Surg 2014;98:574-580; discussion 580-581.

26 Avgerinos DV, Charitakis K: Hybrid coronary revascularization: present and future. Hellenic J Cardiol 2015;56:193-196.

27 Harskamp RE, Puskas JD, Tijssen JG, Walker PF, Liberman HA, Lopes RD, Vassiliades TA, Peterson ED, Halkos ME: Comparison of hybrid coronary revascularization versus coronary artery bypass grafting in patients $\geq 65$ years with multivessel coronary artery disease. Am J Cardiol 2014;114:224-229.

28 Halkos ME, Ford L, Peterson D, Bluestein SM, Liberman HA, Kilgo P, Puskas JD, Guyton RA, Chowdhury R: The impact of hybrid coronary revascularization on hospital costs and reimbursements. Ann Thorac Surg 2014;97: 1610-1615; discussion 1615-1616.

29 Yusuf S, Zhao F, Mehta SR, Chrolavicius S, Tognoni G, Fox KK: Effects of clopidogrel in addition to aspirin in patients with acute coronary syndromes without ST-segment elevation. N Engl J Med 2001;345:494-502.

30 Gao P, Xiong H, Zheng Z, Li L, Gao R, Hu SS: Evaluation of antiplatelet effects of a modified protocol by platelet aggregation in patients undergoing "one-stop" hybrid coronary revascularization. Platelets 2010;21:183-190.

- 31 Bonatti J, Schachner T, Bonaros N, Ohlinger A, Danzmayr M, Jonetzko P, Friedrich G, Kolbitsch C, Mair P, Laufer G: Technical challenges in totally endoscopic robotic coronary artery bypass grafting. J Thorac Cardiovasc Surg 2006;131:146-153.

32 Harskamp RE, Vassiliades TA, Mehta RH, de Winter RJ, Lopes RD, Xian Y, Peterson ED, Puskas JD, Halkos ME: Comparative effectiveness of hybrid coronary revascularization vs coronary artery bypass grafting. J Am Coll Surg 2015;221:326-334.e1. 
33 Phan K, Wong S, Wang N, Phan S, Yan TD: Hybrid coronary revascularization versus coronary artery bypass surgery: systematic review and meta-analysis. Int J Cardiol 2015; 179:484-488.

-34 Rosenblum JM, Harskamp RE, Hoedemaker N, Walker P, Liberman HA, de Winter RJ, Vassiliades TA, Puskas JD, Halkos ME: Hybrid coronary revascularization versus coronary artery bypass surgery with bilateral or single internal mammary artery grafts. J Thorac Cardiovasc Surg 2016;151:1081-1089.

- 35 Ueki C, Miyata H, Motomura N, Sakaguchi G, Akimoto T, Takamoto S: Off-pump versus on-pump coronary artery bypass grafting in patients with left ventricular dysfunction. J Thorac Cardiovasc Surg 2016;151:10921098.

36 Adams C, Burns DJP, Chu MWA, Jones PM, Shridar K, Teefy P, Kostuk WJ, Dobkowski WB, Romsa J, Kiaii B: Single-stage hybrid coronary revascularization with long-term follow-up. Eur J Cardiothorac Surg 2014;45: 438-443.

37 Kiaii B, McClure RS, Stewart P, Rayman R, Swinamer SA, Suematsu Y, Fox S, Higgins J, Albion C, Kostuk WJ, Almond D, Sridhar K, Teefy P, Jablonsky G, Diamantouros P, Dobkowski WB, Jones P, Bainbridge D, Iglesias I, Murkin J, Cheng D, Novick RJ: Simultaneous integrated coronary artery revascularization with long-term angiographic follow-up. J Thorac Cardiovasc Surg 2008;136:702-708.

- 38 Ong AT, Serruys PW, Mohr FW, Morice MC, Kappetein AP, Holmes DR Jr, Mack MJ, van den Brand M, Morel MA, van Es GA, Kleijne J, Koglin J, Russell ME: The SYNergy between percutaneous coronary intervention with TAXus and cardiac surgery (SYNTAX) study: design, rationale, and run-in phase. Am Heart J 2006;151:1194-1204.

39 Gulati R, Rihal CS, Gersh BJ: The SYNTAX trial: a perspective. Circ Cardiovasc Interv 2009;2:463-467.

40 Naqvi SY, Klein J, Saha T, McCormick DJ, Goldberg S: Comparison of percutaneous coronary intervention versus coronary artery bypass grafting for unprotected left main coronary artery disease. Am J Cardiol 2017;119: 520-527.
41 Harskamp RE, Abdelsalam M, Lopes RD, Boga G, Hirji S, Krishnan M, Kiljanek L, Mumtaz M, Tijssen JG, McCarty C, de Winter RJ, Bachinsky WB: Cardiac troponin release following hybrid coronary revascularization versus off-pump coronary artery bypass surgery. Interact Cardiovasc Thorac Surg 2014; 19:1008-1012.

42 Taggart DP, Altman DG, Gray AM, Lees B, Nugara F, Yu LM, Flather M: Effects of onpump and off-pump surgery in the Arterial Revascularization Trial. Eur J Cardiothorac Surg 2015;47:1059-1065.

43 Kunt AS, Darcin OT, Andac MH: Coronary artery bypass surgery in high-risk patients. Curr Control Trials Cardiovasc Med 2005;6: 13.

-44 Leacche M, Byrne JG, Solenkova NS, Reagan B, Mohamed TI, Fredi JL, Zhao DX: Comparison of 30-day outcomes of coronary artery bypass grafting surgery versus hybrid coronary revascularization stratified by SYNTAX and euroSCORE. J Thorac Cardiovasc Surg 2013;145:1004-1012.

45 Joo HC, Youn YN, Kwak YL, Yi GJ, Yoo KJ: Intraoperative epiaortic scanning for preventing early stroke after off-pump coronary artery bypass. Br J Anaesth 2013;111:374381.

46 Davis KA, Miyares MA, Dietrich E: Dual antiplatelet therapy with clopidogrel and aspirin after ischemic stroke: a review of the evidence. Am J Health Syst Pharm 2015;72:1623-1629.

47 Weintraub WS, Grau-Sepulveda MV, Weiss JM, O’Brien SM, Peterson ED, Kolm P, Zhang Z, Klein LW, Shaw RE, McKay C, Ritzenthaler LL, Popma JJ, Messenger JC, Shahian DM, Grover FL, Mayer JE, Shewan CM, Garratt KN, Moussa ID, Dangas GD, Edwards FH: Comparative effectiveness of revascularization strategies. N Engl J Med 2012;366:1467-1476.

48 Hannan EL, Zhong Y, Berger PB, Walford G, Curtis JP, Wu C, Venditti FJ, Higgins RS, Smith CR, Lahey SJ, King SB 3rd: Comparison of intermediate-term outcomes of coronary artery bypass grafting versus drug-eluting stents for patients $\geq 75$ years of age. Am J Cardiol 2014;113:803-808

49 Zhao DX, Leacche M, Balaguer JM, Boudoulas KD, Damp JA, Greelish JP, Byrne JG,
Ahmad RM, Ball SK, Cleator JH, Deegan RJ, Eagle SS, Fong PP, Fredi JL, Hoff SJ, Jennings HS 3rd, McPherson JA, Piana RN, Pretorius M, Robbins MA, Slosky DA, Thompson A: Routine intraoperative completion angiography after coronary artery bypass grafting and 1-stop hybrid revascularization results from a fully integrated hybrid catheterization laboratory/operating room. J Am Coll Cardiol 2009; 53:232-241.

50 Sepehripour AH, Chaudhry UA, Suliman A, Kidher E, Sayani N, Ashrafian H, Harling L, Athanasiou T: How revascularization on the beating heart with cardiopulmonary bypass compares to off-pump? A meta-analysis of observational studies. Interact Cardiovasc Thorac Surg 2016;22:63-71.

51 Hiesinger W, Atluri P: Hybrid coronary revascularization: ready for prime time, but who should star? J Thorac Cardiovasc Surg 2016;151:1090-1091.

52 Myles PS, Smith JA, Forbes A, Silbert B, Jayarajah M, Painter T, Cooper DJ, Marasco $\mathrm{S}$, McNeil J, Bussières JS, McGuinness $\mathrm{S}$, Byrne K, Chan MTV, Landoni G, Wallace S: Tranexamic acid in patients undergoing coronary-artery surgery. N Engl J Med 2017;376: 136-148.

53 Nawarskas JJ, Clark SM: Ticagrelor: a novel reversible oral antiplatelet agent. Cardiol Rev 2011;19:95-100.

54 Gutierrez JA, Harrington RA, Blankenship JC, Stone GW, Steg PG, Gibson CM, Hamm CW, Price MJ, Genereux P, Prats J, Deliargyris EN, Mahaffey KW, White HD, Bhatt DL: The effect of cangrelor and access site on ischaemic and bleeding events: insights from CHAMPION PHOENIX. Eur Heart J 2016; 37:1122-1130.

55 Puskas JD, Halkos ME, DeRose JJ, Bagiella E, Miller MA, Overbey J, Bonatti J, Srinivas V, Vesely M, Sutter F, Lynch J, Kirkwood K, Shapiro TA, Boudoulas KD, Crestanello J, Gehrig T, Smith P, Ragosta M, Hoff SJ, Zhao D, Gelijns AC, Szeto WY, Weisz G, Argenziano M, Vassiliades T, Liberman H, Matthai W, Ascheim DD: Hybrid coronary revascularization for the treatment of multivessel coronary artery disease: a multicenter observational study. J Am Coll Cardiol 2016;68:356-365. 